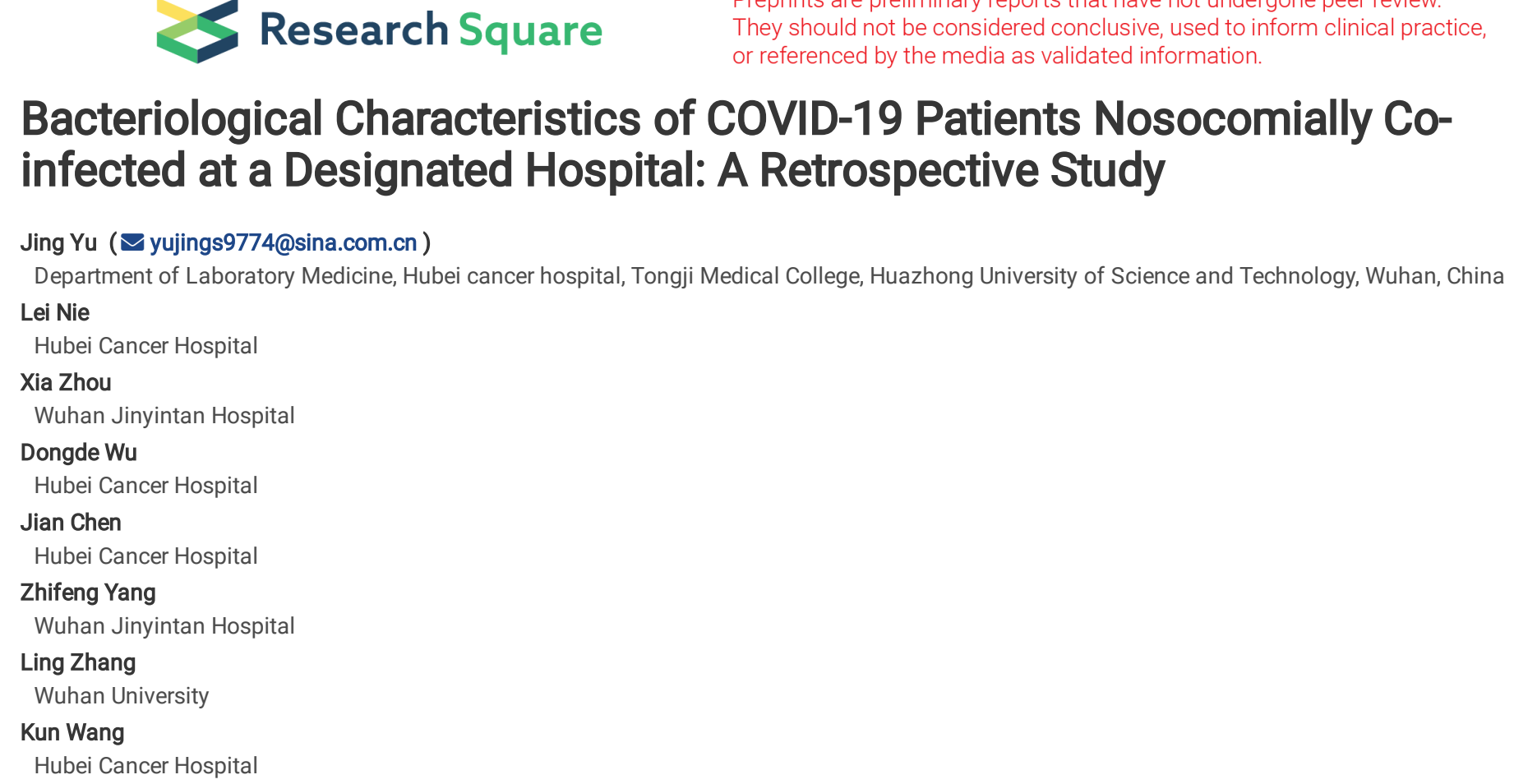

\section{Bacteriological Characteristics of COVID-19 Patients Nosocomially Co- infected at a Designated Hospital: A Retrospective Study}




\section{Abstract}

Background: Bacterial co-infection in patients infected with severe acute respiratory syndrome coronavirus 2 (SARS-CoV-2) is a critical factor that increases the complexity and treatment of coronavirus disease 2019 (COVID-19).

Methods: We collected the clinical laboratory data of 1799 patients with confirmed COVID-19 who were admitted to Jinyintan Hospital in Wuhan, China, between January 1 to April 26, 2020. The bacterial co-infection along with disease progression was analyzed. Other inflammatory markers, including Creactive protein (CRP), white blood cells (WBC), lymphocytes $(\mathrm{L})$, neutrocytes $(\mathrm{N})$, interleukin-6 (IL-6), and procalcitonin (PCT), were assessed to estimate the progression of COVID-19.

Results: We found that 191 of the 1799 (10.62\%) patients had bacterial co-infection. The most prevalent causative agents for bacterial co-infection were Klebsiella pneumoniae (91 cases, 5.06\%) and Acinetobacter baumannii (66 cases, 3.67\%). The most patients with bacterial co-infection showed extensive drug-resistance. The outcomes of patients with bacterial co-infection were worse than those of patients without bacterial co-infection.

Conclusions: Secondary bacterial pneumonia during virus infection is a major risk factor for high mortality resulting from severe pneumonia caused by COVID19.

\section{Background}

Severe adult respiratory syndrome coronavirus 2 (SARS-CoV-2) is responsible for 2019 novel coronavirus disease (now referred to as COVID-19)[1]. By August 1st, 2020, there were more than 20 million confirmed cases of COVID-19 and 700,000 deaths across 215 countries, areas, or territories. The World health organization(WHO) reported that $80 \%$ of the confirmed COVID-19 patients in China had mild or moderate disease, while nearly $14 \%$ of the patients developed severe disease and $5 \%$ developed critically severe disease. The mortality of the critically severe patients was over $50 \%$, and the cause of death was a series of complications including inflammatory storm, coagulation dysfunction, septic shock, and multiple organ failure. Some findings indicate that COVID-19 patients often have infection with other respiratory viruses, such as influenza virus[2, 3]. Additionally, in hospitalized patients with COVID-19, sepsis with bacteremia is one of the severe complications, and secondary bacterial pneumonia has also been observed[4]. Bacterial co-infection in COVID-19 patients may increase the complexity of the patient's condition and necessitate more treatment. However, the susceptible bacteria of COVID-19 patients nosocomially co-infected and outcome hasn't been reported. Here, we retrospectively explored the bacteriological characteristics and prognosis of COVID-19 patients who were nosocomially co-infected at Jinyintan Hospital, which is a designated hospital for COVID-19 patients in Wuhan, China.

\section{Methods}

Patients and diagnosis of COVID-2019 and bacterial infection

Bacteriological data were retrospectively collected from 1799 patients with SARS-CoV-2 infection who were hospitalized at Jinyintan Hospital between January and April 2020. All the patients had a confirmed COVID-19 diagnosis that was based on typical imaging features, etiological evidence, and epidemiological history. Throat swabs of the enrolled patients were used for SARS-Cov-2 RNA (Ribonucleic Acid) detection by real-time polymerase chain reaction with the nucleic acid extraction kit (Zhijiang Gene Company, Shanghai, China) and the 2019-nCoV ORFlab/N gene target detection kit (Zhijiang Gene Company, Shanghai, China). According to the seventh edition of the COVID-19 diagnosis and treatment protocol of China, the disease was classified into four types-mild, moderate, severe, and critical-based on the clinical conditions of the patients.

A 5-ml sample of sterile anticoagulant venous blood was drawn into a special culture bottle for detection of bacteremia (Becton, Dickinson Company, USA). Further, samples of urine, sputum, stool, and bronchoalveolar lavage fluid were collected in sterilized containers and used for bacterial culture. Bacterial culture was performed using a carbon dioxide incubator (Thermo Fisher, USA) and culture medium (Dijing Microbe Technology Company, Guangzhou, China). Bacterial identification and drug sensitivity tests were performed using the VITEK 2 Compact Identification System (Biomerieux Company, USA) and its corollary card. The serum 1-3- $\beta-D$ glucan test and Aspergillus galactose mannose test ( $\mathrm{G}$ and $\mathrm{Gm}$ tests) were used for fungal detection with the Tianjin Danna $\mathrm{G}$ and $\mathrm{Gm}$ testing system (Danna Biotechnology Company, Tianjin, China).

Statistical analysis was performed with SPSS version 20.0 (IBM Corp., Armonk, NY, USA). The t-test and chi-square test were used to analyze the differences between COVID-19 patients with various bacterial co-infections. The Pearson correlation test and Spearman rank correlation test were used for analyzing the associations between individual patient variables. $\mathrm{P}<0.05$ was considered to indicate statistical significance. Independent prognostic factors were identified by univariate and multivariate Cox regression analysis. Nomograms for overall survival (OS) probability were created using the R software (version 3.4.4).

\section{Results}

Demographic characteristics

According to the clinical data of 153 of 1799 COVID-2019 patients, 35 had moderate disease, 81 had severe disease, and 37 had critically severe disease which were showed in Table 1. Of the 153 patients, 63 were female and 90 were male. All patients were in the age range of 35-91 years, with a mean age of 63.94 years. Around $49.67 \%$ (76) of the patients were over 65 years old. In our study, no significant differences in CEA and C-reactive protein (CRP), white blood cells (WBC), lymphocytes (L), neutrocytes (N), interleukin-6 (IL-6), and procalcitonin (PCT) according to sex and age were observed. 
Table 1

The clinical characteristic materials of 153 COVID-19 patients

\begin{tabular}{|c|c|c|c|c|c|c|c|c|}
\hline Group & $\mathbf{N}$ & IL-6 & WBC & $L \%$ & $\mathrm{~N} \%$ & CRP & PCT & CEA \\
\hline \multicolumn{9}{|l|}{ Sex } \\
\hline Male & 90 & $21.87 \pm 4.65$ & $10.11 \pm 0.67$ & $11.36 \pm 1.0$ & $82.25 \pm 1.26$ & $78.52 \pm 7.52$ & $1.44 \pm 0.44$ & $12.39 \pm 1.66$ \\
\hline Female & 63 & $11.23 \pm 1.70$ & $10.44 \pm 0.76$ & $13.42 \pm 1.30$ & $80.1 \pm 1.64$ & $72.72 \pm 10.45$ & $0.96 \pm 0.47$ & $16.31 \pm 1.93$ \\
\hline$P$ value & & 0.078 & 0.75 & 0.20 & 0.30 & 0.65 & 0.46 & 0.13 \\
\hline \multicolumn{9}{|l|}{ Age } \\
\hline$\geq 65$ & 76 & $21.28 \pm 4.99$ & $10.33 \pm 0.69$ & $11.17 \pm 1.01$ & $82.93 \pm 1.32$ & $79.59 \pm 8.20$ & $1.42 \pm 0.47$ & $15.27 \pm 1.99$ \\
\hline$<65$ & 77 & $13.39 \pm 2.36$ & $10.15 \pm 0.74$ & $13.35 \pm 1.25$ & $79.65 \pm 1.52$ & $72.39 \pm 9.27$ & $1.03 \pm 0.44$ & $12.83 \pm 1.52$ \\
\hline$P$ value & & 0.23 & 0.76 & 0.17 & 0.10 & 0.56 & 0.30 & 0.87 \\
\hline \multicolumn{9}{|l|}{$\begin{array}{l}\text { The admission } \\
\text { classification }\end{array}$} \\
\hline Moderate & 35 & $17.57 \pm 5.60$ & $7.71 \pm 0.62$ & $17.15 \pm 1.73$ & $76.16 \pm 2.06$ & $55.34 \pm 11.38$ & $0.23 \pm 0.13$ & $12.29 \pm 1.95$ \\
\hline severe & 81 & $17.33 \pm 4.03$ & $10.17 \pm 0.68$ & $11.89 \pm 1.0$ & $81.31 \pm 1.29$ & $71.49 \pm 7.68$ & $1.13 \pm 0.38$ & $13.58 \pm 1.52$ \\
\hline Critical severe & 37 & $19.04 \pm 6.83$ & $13.16 \pm 1.22$ & $7.66 \pm 1.43$ & $87.16 \pm 1.96$ & $112 \pm 14.86$ & $2.85 \pm 1.20$ & $19.53 \pm 4.95$ \\
\hline$P$ value & & $\begin{array}{l}0.89^{\star}, 0.91^{\&} \\
0.83^{\#}\end{array}$ & $\begin{array}{l}0.03^{\star}, 0.00^{\&} \\
0.19^{\#}\end{array}$ & $\begin{array}{l}0.39^{\star}, 0.00^{\&} \\
0.02^{\#}\end{array}$ & $0.03^{\star}, 0.00^{\&}, 0.02^{\#}$ & $0.88^{\star}, 0.00^{\&}, 0.01^{\#}$ & $0.14^{\star}, 0.02^{\&}, 0.07^{\#}$ & $0.61^{\star}, 0.11^{\&}, 0.13^{\#}$ \\
\hline \multicolumn{9}{|l|}{$\begin{array}{l}\text { Bacteria co- } \\
\text { infection }\end{array}$} \\
\hline Negative & 74 & $14.74 \pm 3.04$ & $8.22 \pm 0.59$ & $13.81 \pm 1.08$ & $79.8 \pm 1.35$ & $64.18 \pm 8.15$ & $0.18 \pm 0.07$ & $11.82 \pm 1.34$ \\
\hline Positive & 79 & $20.06 \pm 4.71$ & $11.82 \pm 0.72$ & $10.93 \pm 1.13$ & $82.62 \pm 1.44$ & $86.03 \pm 8.84$ & $2.13 \pm 0.57$ & $16.28 \pm 2.09$ \\
\hline$P$ value & & 0.37 & 0.00 & 0.08 & 0.01 & 0.09 & 0.04 & 0.03 \\
\hline
\end{tabular}

The correlation between bacterial co-infection and clinical classification of COVID-19 patients

The findings showed that 191 of the 1799 COVID-2019 patients (10.62\%) were positive for bacterial co-infection at Wuhan Jinyintan Hospital between January 1 and April 26, 2020. The most prevalent causative agents for bacterial co-infection were Klebsiella pneumoniae (91 cases, $5.06 \%$ ) and Acinetobacter baumannii (66 cases, 3.67\%). The other common bacterial species were Stenotrophomonas maltophilia (22 cases, $1.22 \%$ ), Pseudomonas aeruginosa (21 cases, $1.17 \%$ ), Staphylococcus epidermidis (16 cases, $0.89 \%)$, Enterococcus faecium (14 cases, $0.78 \%$ ), Escherichia coli ( 13 cases, $0.72 \%)$, Staphylococcus aureus (12 cases, $0.67 \%$ ), Enterococcus casselifavus (10 cases, $0.56 \%$ ), and Candida parapsilosis ( 9 cases, $0.5 \%$ ). Some of the other bacteria identified were Candida albicans (7 cases, $0.39 \%)$, Smooth albicans ( 6 cases, $0.33 \%)$, Staphylococcus haemolyticus (6 cases, $0.33 \%)$, and Enterobacter agglomerans (5 cases, $0.28 \%)$.

From January to April 2020, bacteria co-infection increased dramatically and reached a peak in the second week of February; this trend was similar to that for hospital admission of COVID-19 patients (Fig. 1A). The bacterial strains identified each week are shown in Fig. 1B.

The incidence of bacterial co-infection in patients with severe disease $(\mathrm{n}=81)$ was significantly higher than that in patients with moderate disease $(44.44 \%$ [36/81] vs. $22.86 \%$ [8/35], $\mathrm{P}=0.037)$, and the patients with critically severe disease also had a higher incidence of bacterial co-infection than those with moderate disease $(64.86 \%$ [24/37] vs. $22.86 \%$ [8/35], $P<0.001)$. Furthermore, the incidence of bacterial infection in the critically severe patients was significantly higher than that in severe patients $(P=0.048)$.

Previous studies have reported that the levels of inflammatory indicators were associated with the severity of COVID-19[5-7]. Therefore, in this study, we also investigated the correlation of C-reactive protein (CRP), white blood cells (WBC), lymphocytes (L), neutrocytes (N), interleukin-6 (IL-6), and procalcitonin (PCT) with bacterial co-infection in COVID-19 patients. Based on the correlation coefficient values, PCT had the highest correlation, and this was followed by CRP, L\%, IL-6, and N\%, in descending order.

The antibiotic resistance of bacteria co-infection with COVID-19

K. pneumoniae is resistant to carbapenems, A. baumannii shows multidrug resistance, and Staphylococcus species show methicillin resistance. The details of drug resistant rate of primary 8 bacteria to antibiotics in our study are shown in Table 2 . The patients with $K$. pneumoniae co-infection showed extensive drugresistance but responded to treatment with meropenem and ceftazidine sulbactam, and the patients co-infected with the multidrug-resistant $A$. baumannii responded to polymyxin B and minocycline. Furthermore, we found that multiple bacterial infections were common in patients with severe COVID-19. 
Table 2

Drug resistant rate of primary 8 bacteria to antibiotics in patients with COVID-19 from January to April in Jinyinta

\begin{tabular}{|c|c|c|c|c|c|c|c|c|c|c|c|c|c|c|c|c|c|}
\hline \multirow[t]{2}{*}{ antibiotics } & \multicolumn{3}{|c|}{$\begin{array}{l}\text { Klebsiella } \\
\text { pneumoniae }\end{array}$} & \multicolumn{3}{|c|}{$\begin{array}{l}\text { Acinetobacter } \\
\text { baumannii }\end{array}$} & \multicolumn{3}{|c|}{$\begin{array}{l}\text { Stenotrophomonas } \\
\text { maltophilia }\end{array}$} & \multicolumn{3}{|c|}{$\begin{array}{l}\text { Pseudomonas } \\
\text { aeruginosa }\end{array}$} & \multicolumn{3}{|c|}{$\begin{array}{l}\text { Staphylococcus } \\
\text { epidermidis }\end{array}$} & \multicolumn{2}{|c|}{$\begin{array}{l}\text { enterococcu: } \\
\text { faecium }\end{array}$} \\
\hline & $\mathrm{R} \%$ & $\mid \%$ & $\mathrm{~s} \%$ & $\mathrm{R} \%$ & $1 \%$ & $\mathrm{~S} \%$ & $\mathrm{R} \%$ & $\mid \%$ & S\% & $\mathbf{R} \%$ & $1 \%$ & S\% & $\mathbf{R} \%$ & $1 \%$ & s\% & $\mathbf{R} \%$ & $1 \%$ \\
\hline Amikacin & 80.9 & 0 & 19.1 & 89 & 1.1 & 9.9 & 2.1 & 2.1 & 95.8 & - & - & - & 0 & 4.8 & 95.2 & - & - \\
\hline Ampicillin & 100 & 0 & 0 & - & - & - & - & - & - & - & - & - & - & - & - & 100 & 0 \\
\hline Ampicillin/Sulbactam & 83.6 & 3.1 & 13.3 & 86.6 & 3.5 & 9.9 & - & - & - & - & - & - & - & - & - & - & - \\
\hline Polymyxin B & 0 & 0 & 100 & 4.1 & 0 & 95.9 & - & - & - & 2.1 & 0 & 97.9 & - & - & - & - & - \\
\hline Cotrimoxazole & 39.1 & 0 & 60.9 & 86 & 0 & 14 & 30.3 & 0 & 69.7 & - & - & - & 4.8 & 0 & 95.2 & - & - \\
\hline Ciprofloxacin & 83.1 & 0 & 16.9 & 90.1 & 0.6 & 9.3 & - & - & - & 6.4 & 4.2 & 89.4 & - & - & - & 100 & 0 \\
\hline Meropenem & 80 & 0 & 20 & 86.6 & 1.8 & 11.6 & - & - & - & 4.3 & 27.7 & 68.0 & - & - & - & - & - \\
\hline Minocycline & 5.8 & 3.6 & 90.7 & 9.9 & 23.2 & 66.9 & 3 & 3 & 94 & - & - & - & - & - & - & 0 & 37.5 \\
\hline Gentamicin & 83.1 & 0 & 16.9 & 93 & 0 & 7 & - & - & - & 8.5 & 0 & 91.5 & 28.6 & 0 & 71.4 & 64.3 & 0 \\
\hline Ticacillin/bar acid & 84 & 1.8 & 14.2 & 87.2 & 1.2 & 11.6 & 57.6 & 18.2 & 24.2 & 8.5 & 51.1 & 40.4 & - & - & - & - & - \\
\hline Ceftriaxone & 85.8 & 0 & 14.2 & 88.8 & 3.7 & 7.5 & - & - & - & - & - & - & - & - & - & - & - \\
\hline Ceftazidime & 85.3 & 0.5 & 14.2 & 88.4 & 1.7 & 9.9 & 90.9 & 3 & 6.1 & 8.5 & 8.5 & 83 & - & - & - & - & - \\
\hline Cefoxitin & 80.9 & 0.9 & 18.2 & - & - & - & - & - & - & - & - & - & 0 & 42.9 & 57.1 & - & - \\
\hline Cefuroxime & 85.8 & 0.4 & 13.8 & - & - & - & - & - & - & - & - & - & - & - & - & - & - \\
\hline Cefepime & 82.2 & 1.8 & 16 & 89.5 & 2.4 & 8.1 & - & - & - & 6.4 & 2.1 & 91.5 & - & - & - & - & - \\
\hline Cefoperazone/sulbactam & 77.8 & 3.1 & 19.1 & 23.8 & 44.2 & 32 & - & - & - & 2.1 & 6.4 & 91.5 & - & - & - & - & - \\
\hline Cefazolin & 85.8 & 0.4 & 13.8 & - & - & - & - & - & - & - & - & - & - & - & - & - & - \\
\hline Tobramycin & - & - & - & 93.8 & 0 & 6.2 & - & - & - & 6.4 & 2.1 & 91.5 & - & - & - & - & - \\
\hline Imipenem & 79.6 & 2.2 & 18.2 & 77.3 & 11.6 & 11 & - & - & - & 8.5 & 17 & 74.5 & - & - & - & - & - \\
\hline Levofloxacin & 82.2 & 0.5 & 17.3 & 84.9 & 5.8 & 9.3 & 48.5 & 6 & 45.5 & 6.4 & 4.2 & 89.4 & 76.2 & 9.5 & 14.3 & 100 & 0 \\
\hline Macrodantin & 88.9 & 0 & 11.1 & - & - & - & - & - & - & - & - & - & - & - & - & 62.5 & 25 \\
\hline Piperacillin & - & - & - & 89.2 & 1.6 & 9.2 & - & - & - & 8.5 & 19.2 & 72.3 & - & - & - & - & - \\
\hline Piperacillin/tazobactam & 80 & & 20 & 86 & 1.8 & 12.2 & - & - & - & 4.3 & 12.8 & 83 & - & - & - & - & - \\
\hline Aztreonam & - & - & - & - & - & - & - & - & - & 6.4 & 29.8 & 63.8 & - & - & - & - & - \\
\hline Norfloxacin & - & - & - & - & - & - & - & - & - & 0 & 0 & 100 & - & - & - & - & - \\
\hline Azithromycin & - & - & - & - & - & - & - & - & - & - & - & - & 47.6 & 0 & 52.4 & - & - \\
\hline Oxacillin & - & - & - & - & - & - & - & - & - & - & - & - & 71.4 & 0 & 28.6 & - & - \\
\hline Erythromycin & - & - & - & - & - & - & - & - & - & - & - & - & 38.1 & 9.5 & 52.4 & 83.3 & 16.7 \\
\hline Clarithromycin & - & - & - & - & - & - & - & - & - & - & - & - & 38.1 & 4.8 & 57.1 & - & - \\
\hline Clindamycin & - & - & - & - & - & - & - & - & - & - & - & - & 66.7 & 0 & 33.3 & - & - \\
\hline Rifampicin & - & - & - & - & - & - & - & - & - & - & - & - & 14.3 & 0 & 85.7 & 85.8 & 7.1 \\
\hline Linezolid & - & - & - & - & - & - & - & - & - & - & - & - & 38.1 & 0 & 61.9 & 0 & 0 \\
\hline Moxifloxacin & - & - & - & - & - & - & - & - & - & - & - & - & 61.9 & 9.5 & 28.6 & - & - \\
\hline Penicillin & - & - & - & - & - & - & - & - & - & - & - & - & 76.2 & 0 & 23.8 & 100 & 0 \\
\hline Tetracycline & - & - & - & - & - & - & - & - & - & - & - & - & 28.6 & 4.8 & 66.7 & 62.5 & 0 \\
\hline Tigecycline & - & - & - & - & - & - & - & - & - & - & - & - & 0 & 0 & 100 & - & - \\
\hline Teicoplanin & - & - & - & - & - & - & - & - & - & - & - & - & 0 & 0 & 100 & 0 & 0 \\
\hline Vancomycin & - & - & - & - & - & - & - & - & - & - & - & - & 0 & 0 & 100 & 0 & 0 \\
\hline
\end{tabular}




\begin{tabular}{|c|c|c|c|c|c|c|c|c|c|c|c|c|c|c|c|c|c|}
\hline \multirow[t]{2}{*}{ antibiotics } & \multicolumn{3}{|c|}{$\begin{array}{l}\text { Klebsiella } \\
\text { pneumoniae }\end{array}$} & \multicolumn{3}{|c|}{$\begin{array}{l}\text { Acinetobacter } \\
\text { baumannii }\end{array}$} & \multicolumn{3}{|c|}{$\begin{array}{l}\text { Stenotrophomonas } \\
\text { maltophilia }\end{array}$} & \multicolumn{3}{|c|}{$\begin{array}{l}\text { Pseudomonas } \\
\text { aeruginosa }\end{array}$} & \multicolumn{3}{|c|}{$\begin{array}{l}\text { Staphylococcus } \\
\text { epidermidis }\end{array}$} & \multicolumn{2}{|c|}{$\begin{array}{l}\text { enterococcu: } \\
\text { faecium }\end{array}$} \\
\hline & $\mathrm{R} \%$ & $1 \%$ & S\% & $\mathrm{R} \%$ & $1 \%$ & $\mathrm{~S} \%$ & $\mathrm{R} \%$ & $1 \%$ & $\mathrm{~S} \%$ & $\mathrm{R} \%$ & $1 \%$ & $\mathrm{~S} \%$ & $\mathrm{R} \%$ & $1 \%$ & S\% & $\mathrm{R} \%$ & $1 \%$ \\
\hline $\begin{array}{l}\text { Streptomycin (high } \\
\text { concentration) }\end{array}$ & - & - & - & - & - & - & - & - & - & - & - & - & - & - & - & 28.6 & 0 \\
\hline
\end{tabular}

Note: Letter “R”presents resistance; letter "S" presents sensitive; letter "I” presents intermediary.

The prognostic nomogram of COVID-19 patients with bacterial co-infection

The prognostic nomogram of COVID-19 patients with bacterial co-infection was analyzed in our research. The survival curves of patients with COVID-19 with or without bacterial co-infection are shown in Fig. 1C. We found that the outcomes of patients with bacterial co-infection were worse than those of patients without bacterial co-infection $(P=0.032)$.

According to the findings of our previous study, carcinoembryonic antigen (CEA) is a prognostic marker of COVID-19[8]; therefore, CEA was included in the present nomogram analysis. Based on the multivariate analysis conducted in the present study, a prognostic nomogram for OS of COVID-19 patients with bacterial co-infection was created (Fig. 1D). Each predictor in the nomogram was assigned a score (top scale), and the sum of these scores indicated the probability of 1 - and 2-month OS (bottom scale). The c-index for the nomogram of OS was $0.90(95 \% \mathrm{Cl}=0.85-0.96)$, which is indicative of the discriminative ability of the models (Admission classification + bacteria + WBC + Neu\%+PCT + CEA, Fig. 1D).

\section{Discussion}

In the present study, we describe a typical cohort of COVID-19 patients who were co-infected with bacteria during their progression and therapy. Secondary bacterial pneumonia during virus infection is a major risk factor for high mortality resulting from severe pneumonia[9, 10]. Based on the evidence from previous outbreaks of severe acute respiratory syndrome (SARS) and Middle East respiratory syndrome (MERS), secondary infection rates with bacteria increase mortality as a result of immunosuppression by corticosteroids[11].

The median duration from admission to detection of bacteria was 6 days. We found that in most 153 cases, bacterial co-infection with SARS-CoV-2 occurred after the application of invasive mechanical ventilation and administration of antibiotics and glucocorticoids. In addition, bacteria co-infection was associated with high levels of antibiotic resistance; for instance, $K$. pneumoniae is resistant to carbapenems, $A$. baumannii shows multidrug resistance, and Staphylococcus species show methicillin resistance. In this study, we analyzed the details of drug resistant rate of primary 8 bacteria to antibiotics. Given these variations in the clinical features of the patients, it was essential to assess the bacteria co-infection and adjust the therapeutic strategies so as to prevent drug resistance and improve prognosis.

Additionally, prior antibiotic use is also a risk factor for bacterial co-infection in COVID-19 patients. The hospital environment is a reservoir for bacteria. Medical equipment, especially that used for invasive mechanical ventilation, is one of the important risk factors that predispose patients to infection with bacteria. Accordingly, in the present study, we found that the application of invasive mechanical ventilation and administration of antibiotics and glucocorticoids were risk factors for bacterial co-infection in COVID-19. Additionally, upon infection, SARS-CoV-2 virus triggers the innate immune response in host cells[9, 12]. Therefore, SARS-CoV-2 infection itself can enhance susceptibility to bacterial co-infection.

\section{Conclusions}

In summary, K. pneumoniae and A. baumannii were the most prevalent bacteria responsible for co-infection. However, the causative species might be different at another hospital. Fungal co-infection also occurred after prolonged administration of antibiotics. Our work aimed to estimate bacterial co-infection in patients infected with SARS-CoV-2. We identified the common bacterial species responsible for nosocomial co-infection at a designated COVID-19 hospital, and we also describe the antibiotic regimens that were used for the treatment of this cohort. Based on the findings, we recommend detection tests for inflammatory markers and bacteria, as well as drug-resistance tests for continuously monitoring patients with COVID-19 during hospitalization for better outcome[13-15].

\section{Abbreviations}

COVID-19 Coronavirus disease 2019

SARS-CoV-2 Severe acute respiratory syndrome coronavirus 2

WHO World health organization

USA United States of America

G test $1-3-\beta-D$ glucan test

Gm test Aspergillus galactose mannose test

OS Overall survival 
CRP C-reactive protein

WBC White blood cell

L Lymphocyte

N Neutrocyte

IL-6 Interleukin-6

PCT Procalcitonin

K. pneumoniae Klebsiella pneumoniae

A. baumannii Acinetobacter baumannii

SARS Severe acute respiratory syndrome

MERS Middle East respiratory syndrome

\section{Declarations}

Acknowledgments

We would like to thank all the medical staff fighting against COVID-2019.

\section{Funding}

This study was supported by a grant from the Health and Family Planning Commission Foundation of Hubei Province awarded to Lei Nie (Grant No. WJ2019H194).

\section{Availability of data and materials}

Not applicable.

\section{Authors' contributions}

Drs. Jing Yu and Xia Zhou had full access to the clinical data and analyzed the data in the study. Drs. Lei Nie and Jing Yu were responsible for the conception and design of the study. Drs. Ling Zhang, Zhifeng Yang and Dongde Wu supervised the study. Drs. Jian Chen and Kun Wang conducted the statistical analysis.

\section{Ethics approval and consent to participate}

This study was approved by the Ethics Committee of Jinyintan Hospital, Wuhan, China. Oral informed consent was obtained from the patients.

\section{Consent for publication}

All the co-authors consent to publish this manuscript.

\section{Competing interests}

The authors have no conflicts of interest to declare.

\section{References}

1. Guan WJ, Ni ZY, Hu Y, Liang WH, Ou CQ, He JX, et al. Clinical Characteristics of Coronavirus Disease 2019 in China. The New England journal of medicine. 2020 Apr 30;382(18):1708-20.

2. Kong WH, Li Y, Peng MW, Kong DG, Yang XB, Wang L, et al. SARS-CoV-2 detection in patients with influenza-like illness. Nature microbiology. 2020 May;5(5):675-8.

3. Zhao J, Liao X, Wang H, Wei L, Xing M, Liu L, et al. Early virus clearance and delayed antibody response in a case of COVID-19 with a history of coinfection with HIV-1 and HCV. Clinical infectious diseases: an official publication of the Infectious Diseases Society of America. 2020 Apr 9.

4. Wu CP, Adhi F, Highland K. Recognition and management of respiratory coinfection and secondary bacterial pneumonia in patients with COVID-19. Cleveland Clinic journal of medicine. 2020 May 11.

5. Wang L. C-reactive protein levels in the early stage of COVID-19. Medecine et maladies infectieuses. 2020 Jun;50(4):332-4.

6. McGonagle D, Sharif K, O'Regan A, Bridgewood C. The Role of Cytokines including Interleukin-6 in COVID-19 induced Pneumonia and Macrophage Activation Syndrome-Like Disease. Autoimmun rev. 2020 Jun;19(6):102537. 
7. Qu R, Ling Y, Zhang YH, Wei LY, Chen X, Li XM, et al. Platelet-to-lymphocyte ratio is associated with prognosis in patients with coronavirus disease-19. Journal of medical virology. 2020 Mar 17.

8. Yu J, Yang Z, Zhou X, Wu D, Chen J, Zhang L, et al. Prognostic value of Carcinoembryonic antigen on outcome in patients with Coronavirus disease 2019. The Journal of infection. 2020 Jun 12.

9. Azkur AK, Akdis M, Azkur D, Sokolowska M, van de Veen W, Brüggen MC, et al. Immune response to SARS-CoV-2 and mechanisms of immunopathological changes in COVID-19. Allergy. 2020 May 12.

10. Hanada S, Pirzadeh M, Carver KY, Deng JC. Respiratory Viral Infection-Induced Microbiome Alterations and Secondary Bacterial Pneumonia. Frontiers in immunology. 2018;9:2640.

11. Rokni M, Ghasemi V, Tavakoli Z. Immune responses and pathogenesis of SARS-CoV-2 during an outbreak in Iran: Comparison with SARS and MERS. Reviews in medical virology. 2020 May;30(3): e2107.

12. Guo YR, Cao QD, Hong ZS, Tan YY, Chen SD, Jin HJ, et al. The origin, transmission and clinical therapies on coronavirus disease 2019 (COVID-19) outbreak - an update on the status. Military Medical Research. 2020 Mar;13(1):11. 7(.

13. Spinelli E, Mauri T, Beitler JR, Pesenti A, Brodie D. Respiratory drive in the acute respiratory distress syndrome: pathophysiology, monitoring, and therapeutic interventions. Intensive care medicine. 2020;46:606-18.

14. Xu Z, Shi L, Wang Y, Zhang J, Huang L, Zhang C, et al. Pathological findings of COVID-19 associated with acute respiratory distress syndrome. The Lancet Respiratory medicine. 2020;8:420-2.

15. Wei X, Su J, Yang K, Wei J, Wan H, Cao X, et al. Elevations of serum cancer biomarkers correlate with severity of COVID-19. Journal of medical virology 2020.

\section{Figures}

A

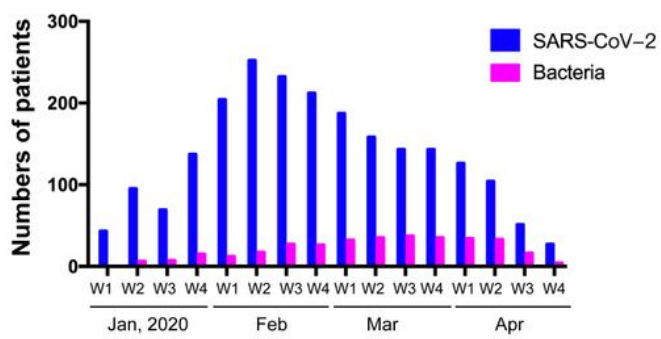

C

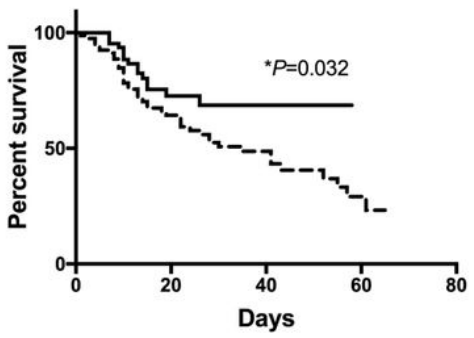

B

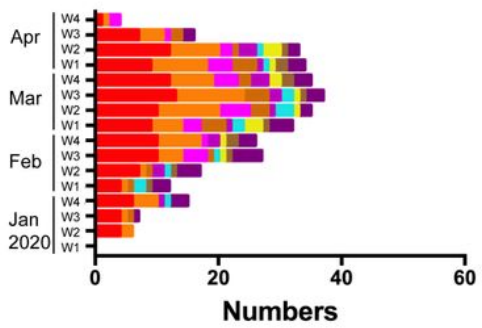

- Negative bacteria
Numbers

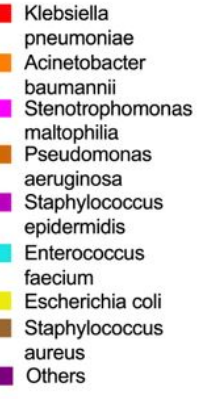

Acinetobacter

maltophilia

Pseudomonas

epidermidis

Enterococcus

faecium

Staphylococcus

Others

-- Positive bacteria

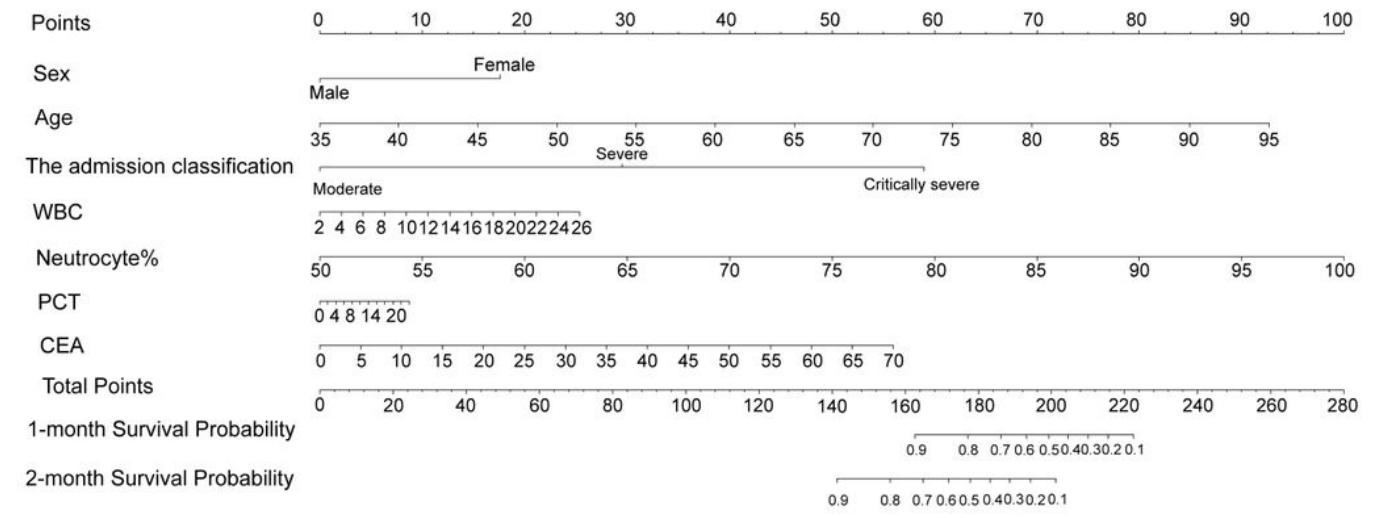

Figure 1

Occurrence of nosocomial bacterial infection in COVID-19 patients. A. The weekly number of reported cases with SARS-CoV-2 and bacterial co-infection, from January 1st to April 26th, 2020, in Jinyintan Hospital, Wuhan, China. W1 to W4 represent the first week to the fourth week of each month. B. The number of cases positive for each bacterial strain every week. C. The survival curve of COVID-19 patients with or without bacterial co-infection. The outcome of patients 
with bacterial co-infection was significantly worse than that of patients without bacterial co-infection $(P=0.032)$. D. Construction of nomogram with CEA and other significant indicators for predicting the probability of overall survival in COVID-19 patients. 